\title{
Diferenças entre os gêneros na assistência técnica e extensão rural realizada por médicos veterinários: paradigma ou preconceito
}

\author{
Sabrina Lucas Ribeiro de Freitas ${ }^{1}$, Morgana Pontes Abreu², Gabriella Riad Iskandar Mesquita, \\ Valéria de Sá Jaime ${ }^{4}$, João Maurício Lucas Gordo ${ }^{5}$ Luiz Antônio Franco da Silva ${ }^{6}$
}

\section{RESUMO}

A Medicina Veterinária é profissão relativamente antiga e, mesmo em tempos modernos, em determinados países ou regiões, a profisssional veterinária ainda encontra barreiras ao exercício pleno da profissão, tanto nas atividades de Assistência Técnica como nas de Extensão Rural. Este estudo objetivou verificar se existem diferenças entre os gêneros, no que se refere às atividades de Assistência Técnica e de Extensão Rural, realizadas por médicos veterinários no Estado de Goiás (Brasil) e, em caso de existência, analisar se os resultados podem ser considerados frutos de um paradigma ou de preconceito. O trabalho foi desenvolvido no Estado de Goiás, em 26 municípios, envolvendo 100 propriedades rurais, administradas por indivíduos de diferentes gêneros e perfis. Foram analisados questionários respondidos pelos proprietários, envolvendo cinco temas, compreendendo diferenças entre os gêneros, senso de organização profissional, relacionamento interpessoal, força física e conhecimento técnico. Na visão dos entrevistados, os homens foram considerados como detentores de maior aptidão para as atividades que exigem força física e, as mulheres, para o trabalho que requer maior senso de organização. Para as outras atividades, ambos os profissionais equipararam-se quanto ao seu desempenho, pois a maioria dos entrevistados alegou não ter preferência, em relação aos aspectos gênero, relacionamento interpessoal e conhecimento teórico. Concluiu-se que as diferenças entre os gêneros, nos desempemhos em Assistência Técnica e em Extensão Rural, realizadas por médicos veterinários no Estado de Goiás, foram identificadas quando os aspectos considerados são a força física e o senso de organização. Nos quesitos preferência pelo homem ou pela mulher, relacionamento interpessoal e conhecimento técnico, não houve distinções. Dessa forma, pode-se considerar a existência de um paradigma, não a de um preconceito.

Palavras-chave: extensionista, homem, Medicina Veterinária, mulher, produtor rural.

\section{ABSTRACT \\ Differences between genders in technical assistance and rural extension performed by veterinarians: paradigm or prejudice}

The Veterinary Medicine is a relatively old profession. In some countries or regions, even in modern times, veterinary women still find obstacles in the profession. This study aimed to evaluate if there are differences between genders in veterinary Technical Assistance as well as in Rural Extension and analyzes whether the results can be considered a paradigm or a prejudice. The research was developed in 100 farms in 26 municipalities in the state of Goias. The farms

\footnotetext{
Recebido para publicação em 23/10/2012 e aprovado em 04/07/2013

${ }^{1}$ Graduanda em Medicina Veterinária. Escola de Veterinária e Zootecnia, Universidade Federal de Goiás, Rodovia Goiânia/Nova Veneza (GO 462), Km 0, Campus Samambaia, 74001-970, Goiânia, Goiás, Brasil. sabrina_medvet@ @otmail.com (autor para correspondência). (Bolsista de Iniciação Científica-IC/CNPq.).

${ }^{2}$ Graduanda em Medicina Veterinária. Escola de Veterinária e Zootecnia, Universidade Federal de Goiás, Rodovia Goiânia/Nova Veneza (GO 462), Km 0, Campus Samambaia, 74001-970, Goiânia, Goiás, Brasil. morganabreu@gmail.com (Bolsista de Iniciação Científica-AT/CNPq.).

${ }^{3}$ Zootecnista. Escola de Veterinária e Zootecnia, Universidade Federal de Goiás, Rodovia Goiânia/Nova Veneza (GO 462), Km 0, Campus Samambaia, 74001-970, Goiânia, Goiás, Brasil.gabriella_zoo@ hotmail.com

${ }^{4}$ Médica Veterinária, Doutora. Escola de Veterinária e Zootecnia, Universidade Federal de Goiás, Rodovia Goiânia/Nova Veneza (GO 462), Km 0, Campus Samambaia, 74001970, Goiânia, Goiás, Brasil. valeria.mg@uol.com.br

${ }^{5}$ Médico Veterinário, Doutor. Escola de Veterinária e Zootecnia, Universidade Federal de Goiás, Rodovia Goiânia/Nova Veneza (GO 462), Km 0, Campus Samambaia, 74001970, Goiânia, Goiás, Brasil. jm.gordo@ hotmail.com

${ }^{6}$ Médico Veterinário, Doutor. Escola de Veterinária e Zootecnia, Universidade Federal de Goiás, Rodovia Goiânia/Nova Veneza (GO 462), Km 0, Campus Samambaia, 74001970, Goiânia, Goiás, Brasil. prof_ufg.dmv@ hotmail.com
} 
were administrated by different genders and profiles. A questionnaire was applied to farmers involving five topics: differences between genders, professional organization, interpersonal relationship, physical strength and technical knowledge. In the interviewees' opinion, men were considered to have more ability for tasks which require physical strength; and women were considered to have more ability than men when the task involves organization. Regarding the other topics (interpersonal relationship, technical knowledge and differences between genders) both professionals were equivalent, because the majority of the interviewees claimed not to have preference for gender. Therefore, it was concluded that the differences between genders in Technical Assistance and Rural Extension performed by veterinarians were identified when it comes to physical strength and organization. In topics preference between men or women, interpersonal relationship and technical knowledge, there was not distinction between the genders. Then, the differences between genders can be considered a paradigm and not a prejudice.

Key words: extension agent, man, veterinary medicine, woman, farmer.

\section{INTRODUÇÃO}

A Medicina Veterinária é profissão relativamente antiga e, mesmo em tempos modernos, em determinados países ou regiões, a mulher veterinária ainda encontra barreiras ao exercício pleno da profissão, tanto no que se refere às atividades de Assistência Técnica como às de Extensão Rural. Portanto, é possível que se percebam diferenças entre os gêneros, quanto à percepção de suas aptidões para a execução de atividades dessa profissão, no campo, que podem resultar em menores oportunidades de trabalho para a mulher veterinária. Para se entender melhor essa situação, é útil conhecer um pouco da história da Medicina Veterinária, a par da evolução da situação social da mulher na história humana recente. A primeira Escola de Veterinária foi criada em Lion, na França, no ano de 1761. No Brasil, a criação de curso superior nessa área ocorreu em 1913, no Estado do Rio de Janeiro. Nessa ocasião, e até as ultimas décadas do século XX, como na maioria das profissões, a admissão das mulheres nessa área era diminuta (Hatschbach, 2011).

Igualmente, a participação das mulheres em determinadas especialidades, como no agronegócio, acontecia de forma reprimida, pois, culturalmente, havia dificuldades relacionadas com o deslocamento necessário para o exercício das atividades. Além disso, por falta de confiança na capacidade profissional das mulheres, os órgãos governamentais e os proprietários rurais davam preferência sistemática ao profissional de sexo masculino. Essa situação apresentou os primeiros sinais de mudanças a partir da Primeira Guerra Mundial (1914-1918), ocasião em que as mulheres tiveram que assumir as responsabilidades dos maridos, que estavam envolvidos diretamente na guerra. A partir desse momento, elas tomaram a frente dos negócios de suas famílias, atitude que hoje tem como reflexo principal as importantes posições ocupadas por elas no mercado de trabalho (Scorzafave \& Menezes-Filho, 2006).
No âmbito do agronegócio, a agricultura familiar é responsável por $38 \%$ do valor bruto da produção originada, detém 74,4\% do pessoal ocupado e é o principal fornecedor de alimento básico para a população (IBGE, 2006). Esse nicho de produção tem a mulher como colaboradora, e seu papel é importante para a produção sustentável, caracterizada, especialmente, pela agricultura orgânica, biodinâmica e agroecológica (Karam, 2004).

Apesar do crescimento substancial e dos resultados positivos obtidos por esse segmento, muito raramente as pesquisas científicas apontam a percentagem de participação dos profissionais da Medicina Veterinária, homens e mulheres, tanto nas atividades de Assistência Técnica como nas de Extensão Rural, de forma a atender a preferência e a real necessidade dos proprietários assistidos. Ainda dentro dessa linha de raciocínio, vale lembrar que existem iniciativas por parte de órgãos governamentais, no sentido de se criarem programas que beneficiem, institucional e financeiramente, os mais diferentes produtores rurais, englobando os assentamentos, as populações tradicionais, a agricultura familiar e as grandes propriedades. Apesar disso, no momento de se aplicarem os recursos financeiros disponibilizados, na maioria das vezes, não se verifica a presença de uma orientação institucional e adequada.

$\mathrm{O}$ fato pode ser atribuído à carência de profissionais com perfil para prestar Assistência Técnica ou Extensão Rural, pela falta de identificação com o trabalho proposto, ou pela rejeição, manifestada pelos produtores quanto às orientações técnicas que não atendam às prioridades das comunidades. Essa situação, devida principalmente à desinstitucionalização da Extensão Rural no País e ausência do Estado no setor, em parte, pode ter relação com a falta de incentivos, por parte dos cursos universitários, à prática da extensão rural, mesmo os mais voltados para a agropecuária, e ainda, um perfil mais urbano do médico veterinário. É evidente a carência de profissionais prepa- 
rados para o trabalho de Extensão Rural e a falta de concursos públicos para contratação de extensionistas e de políticas públicas e recursos financeiros direcionados a essa prática. Não é raro, num determinado município, existir o profissional preparado para realizar atividades técnicas e de extensão, porém sem recursos institucionais e materiais, como programas, veículos, combustíveis e custeio das visitas. Por essa razão, o deslocamento até as propriedades fica custeado pelos profissionais, ou a mercê do auxílio problemático dos interessados.

Mesmo com a criação recente e importante do Programa de Assistência Técnica e Extensão rural (ATER), que busca também minimizar possíveis preferências de gênero, a FAO (2009b) mostrou que os produtores homens têm melhor acesso ao treinamento e à tecnologia, pois faltam extensionistas com habilidades necessárias para trabalhar com as mulheres, que são, muitas vezes, analfabetas. Essas afirmações reproduzem o desempenho precário de determinadas políticas públicas de igualdade de gênero, principalmente, daquelas que visam a incluir, social e economicamente, as mulheres nas ações de produção e no público alvo das ações extensionistas (Bernardo et al., 2010). Todavia, não se pode negar que políticas importantes já procuravam minimizar, no início da década passada essas limitações, como o Programa de Ações Afirmativas, criado em 2002, que, posteriormente, tornou-se o Programa de Promoção de Igualdade de Gênero, Raça e Etnia (PPIGRE), hoje denominado Assessoria de Gênero, Raça e Etnia (AEGRE), cujo objetivo principal é incentivar a aproximação dos gêneros (Pinto, 2006). Por outro lado, uma série de ações estratégicas para a garantia da cidadania das mulheres, englobando direito à terra, aos serviços rurais, ao crédito e à gestão de empreendimentos econômicos, ainda não foi implementada. Diante dessa realidade, é preciso continuar lutando por avanços que confiram maior protagonismo às mulheres, no campo da Assistência Técnica e Extensão Rural, como prestadoras e receptoras, pois nem sempre o trabalho da profissional mulher é aceito em sua plenitude, tanto pelos órgãos governamentais como pelas comunidades assistidas.

Assim, diante da realidade na qual ainda se contempla a existência de diferenças entre os gêneros, também nas atividades de Assistência Técnica e Extensão Rural realizada por diferentes profissionais, incluindo os médicos veterinários, entende-se que é necessário realizar estudos que desmistifiquem o problema, classificando-o apenas como um paradigma, baseando-se, pois, em potencialidades concretas e verificáveis, ou verificando se ele apenas embute um preconceito, em algumas situações. Igualmente, os motivos desse questionamento ainda precisam ser mais bem esclarecidos, tendo em vista que algumas características femininas importantes, como o senso de organização, a simpatia, a boa educação, no sentido de uma suavidade diferencial no trato, o comprometimento e a responsabilidade das profissionais veterinárias parecem ter a preferência de alguns proprietários rurais. É válido ressaltar a importância da participação da mulher nas atividades de produção, não só no setor de frutas e verduras para o abastecimento da casa, como também na criação das aves, no manejo do rebanho bovino, que muitas vezes é tido como papéis exclusivos, ou preferenciais, dos homens (Riethmuller, 2001; Dalmina et al., 2007). Paralelamente, ao se assumirem, como também adequadas às mulheres, essas atividades, que outrora eram realizadas apenas por homens, cria-se um espaço para que as mulheres veterinárias ocupem posições, iguais ou de destaque, na Assistência Técnica e na Extensão Rural.

Assim este trabalho objetivou avaliar possíveis diferenças entre os gêneros, nas atividades de Assistência Técnica e Extensão Rural, realizadas por médicos veterinários do Estado de Goiás e, em caso de verificação dessas diferenças, analisar se os resultados podem ser considerados frutos de um paradigma ou de preconceito.

\section{MATERIAL E MÉTODOS}

O estudo foi desenvolvido no Estado de Goiás e envolveu proprietários rurais, em 26 municípios (Figura 1). As informações sobre possíveis diferenças entre gêneros nas oportunidades de acesso às atividades de Assistência Técnica e Extensão Rural realizadas por médicos veterinários, foram obtidas por meio de questionários preenchidos durante aulas práticas de Patologia Cirúrgica dos Grandes Animais e em visitas realizadas pelo projeto de extensão "Atendimento Clínico e Cirúrgico a Propriedades Rurais do Estado de Goiás, EV-70, da Escola de Veterinária e Zootecnia da Universidade Federal de Goiás", entre os meses de março de 2009 e setembro de 2012. As atividades foram realizadas com a participação de alunos de Graduação e Pós-graduação e autorizadas pelo Comitê de Ética em Pesquisa da UFG, com o número de protocolo 0150/10.

Foram entrevistados, aleatoriamente, 100 proprietários rurais, variando quanto ao gênero, perfil, tipo de produção, tamanho da propriedade, poder econômico, grau de escolaridade e tempo de atividade. Para a escolaridade, foram considerados analfabetos aqueles entrevistados que não tinham completado o ensino fundamental. As perguntas visavam a esclarecer a existência de possíveis impedimentos, quanto ao gênero, no exercício da profissão de médico veterinário, durante a Assistência Técnica e Extensão Rural, sobretudo com relação à aceitação e ao desempenho diferenciado de homens e de mulheres. Na hipótese de se verificarem essas barreiras, buscou-se averiguar se o problema deve ser visto como um 
paradigma ou como um preconceito. Uma das informações relacionava-se com o tipo de atividade que, em tese, os profissionais do sexo masculino desenvolvem durante o trabalho no campo, e que, no entendimento de alguns, a médica veterinária nem sempre pode executar de forma satisfatória, o que dificulta o reconhecimento do seu trabalho pelos diferentes produtores rurais.

Para atender a essa aspiração, o questionário teve como objetivo precípuo averiguar a opinião do proprietário rural em relação aos seguintes temas, a saber: a) diferenças entre os gêneros, b) senso de organização profissional, c) relacionamento interpessoal, d) força física, e) conhecimento técnico-teórico. Três perguntas foram formuladas para cada tema principal, sendo 15 no total. Cada pergunta continha três alternativas, podendo o entrevistado optar pelo profissional mulher, homem ou qualquer dos dois. Os questionários foram aplicados por professores e estu- dantes da Graduação e da Pós-graduação, de ambos os sexos, com intenção de minimizar o efeito do sexo do entrevistador sobre a resposta do proprietário. Quanto ao tema diferença entre os gêneros, as perguntas baseavam-se em situações nas quais era necessário fazer a escolha entre os profissionais, homem e mulher, para assistir a propriedade, sem designar a atividade que seria desenvolvida. Quando o tema era senso de organização, contemplaram-se nas indagações situações em que era necessário um trabalho com muitos detalhes e foi enfatizado que, para programá-lo, era necessário um profissional com habilidades para a organização de materiais e estabelecimento de uma sequência do trabalho a ser realizado.

No âmbito da relação interpessoal, a figura do gênero foi atrelada a outros aspectos: a receptividade, a educação e a simpatia. Outros questionamentos envolveram

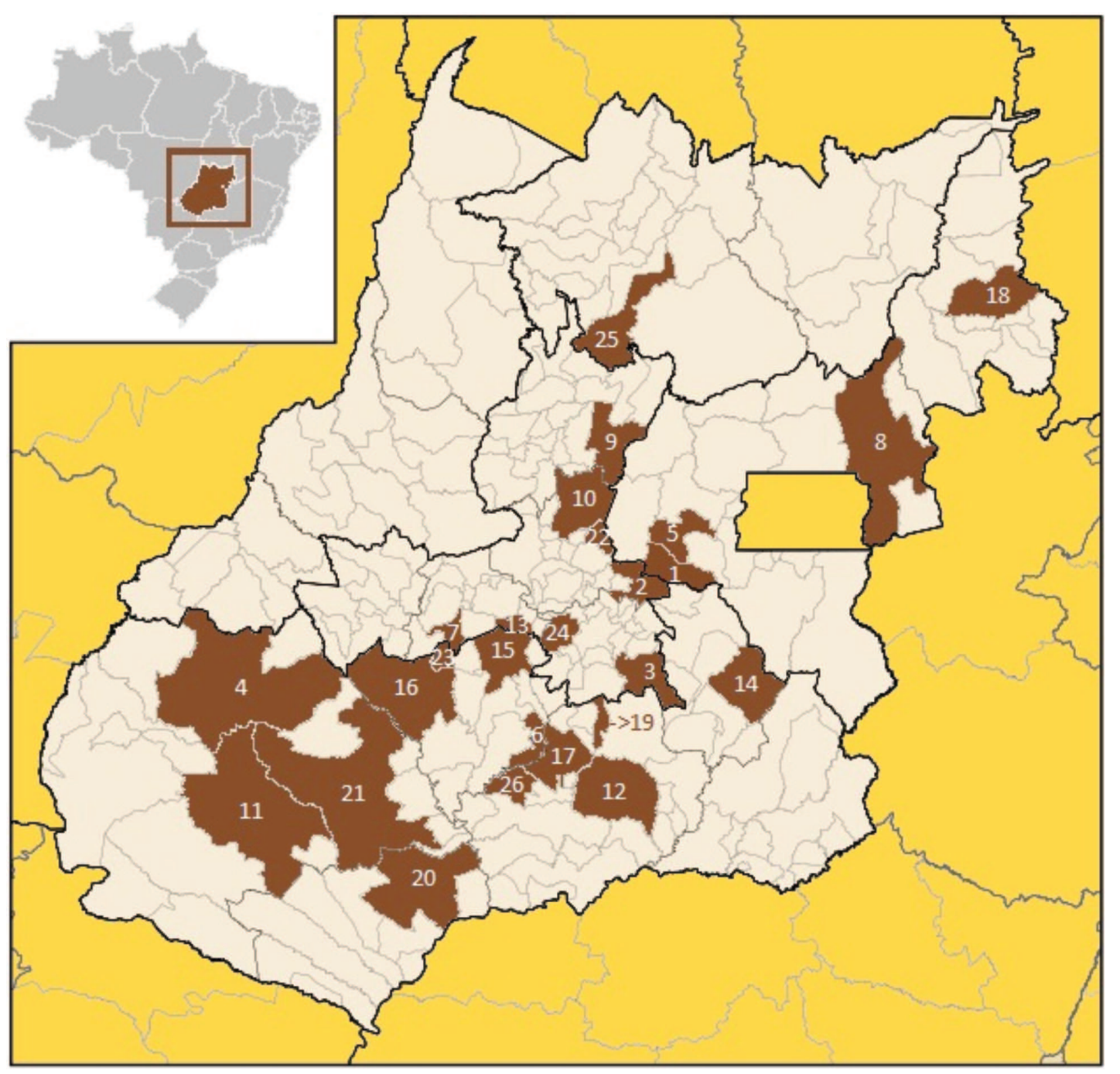

Figura 1. Mapa do Estado de Goiás, indicando os municípios visitados entre março de 2009 e setembro de 2012. 1- Abadiânia, 2- Anápolis, 3- Bela Vista de Goiás, 4- Caiapônia, 5- Corumbá de Goiás, 6- Edealina, 7- Firminópolis, 8- Formosa, 9- Goianésia, 10- Jaraguá, 11- Jataí, 12- Morrinhos, 13- Nazário, 14- Orizona, 15- Palmeiras de Goiás, 16- Paraúna, 17- Pontalina, 18- Posse, 19- Professor Jamil, 20Quirinópolis, 21- Rio Verde, 22- São Francisco de Goiás, 23- São João da Paraúna, 24- Trindade, 25- Uruaçú, 26- Vicentinópolis. Fonte: Adaptado de http://pt.wikipedia.org/wiki/Ficheiro:Goias_Municip_Caiaponia.svg 
atividades que requerem maior força física, como conter animais de grande porte, percorrer grandes extensões de terra, utilizando meios de transporte como animais, ou mesmo percorrer o trajeto a pé, e realizar procedimentos que exigem a força braçal, como extração de fetos bovinos em distocias. Por último, para abordar o conhecimento técnico e a disposição para procurar informações teóricas disponíveis na literatura, foram elaboradas perguntas que envolviam problemas incomuns, em que o profissional precisaria buscar soluções teóricas e práticas, como obter medicamentos extraídos da natureza e preservar o meio ambiente, bem como o desempenho em cursos de extensão.

Os dados foram agrupados em cada questão e as percentagens relacionadas com a alternativa escolhida foram analisadas. Em seguida, calculou-se a média aritmética das três questões de cada tema para se obter o resultado final. Os dados foram analisados descritivamente (Sampaio, 2010).

\section{RESULTADOS}

Do total de propriedades atendidas, 50 (50\%) foram classificadas como pequenos criatórios, 35 (35\%) médios e 15 (15\%) grandes criatórios.

Os dados referentes à percentagem de proprietários rurais entrevistados, quanto ao gênero, à escolaridade e ao tempo de atividade estão dispostos na Tabela 1.

Dentre os 100 proprietários entrevistados, 18 (18\%) eram do sexo feminino e 82 ( $82 \%$ ) do sexo masculino. Quanto às proprietárias, dez $(55,5 \%)$ completaram o ensino médio, sete $(38,9 \%)$ concluíram ensino superior, apenas uma $(5,6 \%)$ tinha completado somente o ensino fundamental e nenhuma era analfabeta. Dos homens entrevistados, $12(14,6 \%)$ eram analfabetos, $19(23,2 \%)$ concluíram o ensino fundamental, $29(35,4 \%)$ tinha como grau de escolaridade o ensino médio e $22(26,8 \%)$ tinham ensino superior.

Todas as mulheres contavam menos de 20 anos de atividade rural. Do total de homens entrevistados, 68 $(82,9 \%)$ praticavam a atividade há mais de 20 anos e apenas $14(17,1 \%)$ não haviam completado duas décadas como produtores rurais.
Na Figura 2, estão representadas as percentagens obtidas de acordo com as alternativas escolhidas pelos entrevistados. Na representação, foram incluídas diferenças entre gêneros (D.G), senso de organização (O), força física (F.F), relação interpessoal (R.I) e conhecimento técnico (C.T).

No que diz respeito ao tema "diferença entre gêneros", $56 \%$ dos entrevistados responderam que não existe diferença entre eles e não tinham preferência, inicialmente, pela escolha de um profissional homem ou mulher. Porém, $44 \%$ responderam que havia diferença, sendo que $30,5 \%$ requeriam o homem e, $13,5 \%$, a mulher. Para o aspecto senso de organização, $33 \%$ opinaram que tanto a mulher quanto o homem são organizados no trabalho do campo, porém a mulher foi indicada como a mais organizada por $47,3 \%$ dos entrevistados contra $19,7 \%$ que elegeram o homem como detentor de mais senso de organização.

Quando o tema era força física, o profissional homem obteve maior percentagem das escolhas $(77,3 \%) \mathrm{em}$ comparação com a mulher, que ficou com apenas $5,7 \%$ dos votos, apesar de, curiosamente, $17 \%$ dos entrevistados acharem que não há diferença entre o gênero para esse quesito.

No quesito relação interpessoal, $40 \%$ compreenderam que tanto o homem quanto a mulher têm boa capacidade de relacionamento interpessoal, ainda que as mulheres tenham obtido $39,7 \%$ dos votos restantes, contra $20,3 \%$ dos homens.

Analisando-se a percepção do quesito conhecimento técnico-teórico, houve equilíbrio entre as alternativas, pois $39 \%$ dos entrevistados acham que tanto a mulher como o homem apresentam desempenho igual, embora $35,3 \%$ entendam que as mulheres estudam mais e apresentam melhor conhecimento teórico, quando comparadas com os homens $(25,6 \%)$.

\section{DISCUSSÃO}

O maior número de proprietários rurais do sexo masculino pode ser atribuído, em parte, à tradição histórica, segundo a qual o homem possui um perfil mais adequado para coordenar um estabelecimento rural ou qualquer outro negócio. Essa percepção é comum, também, entre os

Tabela 1. Distribuição do número de homens e mulheres proprietários rurais, grau de escolaridade e tempo de atividade, após coleta dos dados, entre os meses de março de 2009 e setembro de 2012, em diferentes Municípios do Estado de Goiás

\begin{tabular}{|c|c|c|c|c|c|c|c|}
\hline & \multirow{2}{*}{$\mathbf{N}^{0} \mathbf{P}$. } & \multicolumn{4}{|c|}{ Grau de escolaridade } & \multicolumn{2}{|c|}{ Tempo de atividade } \\
\hline & & An. & E.F. & E.M. & E.S. & $<20$ anos & $>20$ anos \\
\hline Homem & 82 & $\begin{array}{c}12 \\
(14,6 \%)\end{array}$ & $\begin{array}{c}19 \\
(23,2 \%)\end{array}$ & $\begin{array}{c}29 \\
(35,4 \%)\end{array}$ & $\begin{array}{c}22 \\
(26,8 \%)\end{array}$ & $\begin{array}{c}14 \\
(17,1 \%)\end{array}$ & $\begin{array}{c}68 \\
(82,9 \%)\end{array}$ \\
\hline Mulher & 18 & - & $\begin{array}{c}1 \\
(5,6 \%)\end{array}$ & $\begin{array}{c}10 \\
(55,5 \%)\end{array}$ & $\begin{array}{c}7 \\
(38,9 \%)\end{array}$ & $\begin{array}{c}18 \\
(100 \%)\end{array}$ & - \\
\hline
\end{tabular}

No P.: Número de proprietários; An.: Analfabeto; E.F.: Ensino Fundamental; E.M.: Ensino Médio; E.S.: Ensino Superior. 
funcionários de fazendas onde as mulheres são as principais responsáveis por atividades cotidianas da produção de leite, mas não gerenciam o negócio, uma vez que foram tradicionalmente educadas para cuidar da casa, dos filhos e desenvolver apenas pequenas atividades (De Grandi, 2003). Em pesquisa sobre gênero, no Paquistão, foram vistos resultados semelhantes, nos estabelecimentos estudados, pois $75 \%$ dos entrevistados admitiram que as decisões finais nas propriedades são tomadas pelos homens (Arshad et al., 2010). Esses fatos justificam que, dos 100 proprietários entrevistados, 18 (18\%) são do sexo feminino e $82(82 \%)$ do sexo masculino.

Analisando-se o grau de escolaridade, não foi identificada nenhuma mulher analfabeta, entre as que foram entrevistadas. Este resultado é diferente do informado na literatura, a qual afirma que a participação das mulheres em cursos de capacitação é discreta (Rodrigo,1986) e que os produtores homens têm melhor acesso a treinamentos e à tecnologia (FAO, 2009b).

Apesar de percentagem considerável dos homens entrevistados ser de analfabetos, a maior percentagem possuía ensino médio completo e grande parte tinha curso superior, o que difere dos dados encontrados pelo IBGE (2006), segundo os quais $65 \%$ das pessoas que gerenciam estabelecimentos agropecuários possuem somente ensino fundamental e pequena percentagem concluiu o ensino médio e superior.

Ainda sobre a escolaridade, é provável que a maior percentagem de mulheres com maior grau de escolaridade, quando comparado ao dos homens, é devida à incessante procura delas por especialização e aperfeiçoamento profissional. Como consequência disso, elas conquistam os melhores espaços no mercado de trabalho, enquanto as taxas de especializações masculinas permanecem inalteradas (Bruschini \& Lombardi, 2001). Para referendar esse dado, ao se analisar o número de homens e mulheres, médicos veterinários e de profissões afins, matriculados no Curso de Pós-graduação em Ciência Animal da Universidade Federal de Goiás, constata-se que 58,4\% dos alunos são do sexo feminino. Mesmo diante dessa situação, a literatura consultada aponta uma realidade às vezes contraditória. Assim, ainda que exista uma busca das mulheres por maior profissionalização, a desigualdade salarial entre os gêneros prevalece (Macedo \& Santos, 2009).

Analisando-se o tempo ao longo do qual cada entrevistado exercia a atividade rural, argumenta-se, comumente, que o menor tempo das mulheres nessa modalidade de negócio pode ser fruto de limitações impostas ao sexo feminino, cuja liberação recente é fruto de um trabalho demorado. Em alguns países, como a Índia, as mulheres só adquirem poder de decisão nas atividades agropecuárias com o aumento da idade (Gupta et al., 2009). Mas os resultados sinalizam que, no Brasil, o número de mulheres participando do agronegócio vem crescendo a cada dia. Essa situação iniciou-se na década de 80, com a criação do Movimento das Mulheres Agricultoras (MMA), que lutavam pela ascensão do 'status' de "esposas de proprietários rurais" para "proprietárias rurais" (Paulilo, 2003). Portanto, deduz-se que a ascensão conseguida desencadeou mudanças substanciais no processo de inserção da mulher no agronegócio e se refletiu na atuação crescente da médica veterinária nas atividades de Assistência Técnica e Extensão Rural. A literatura é escassa, quando se associa tempo de atividade rural e gênero, porém, sobre

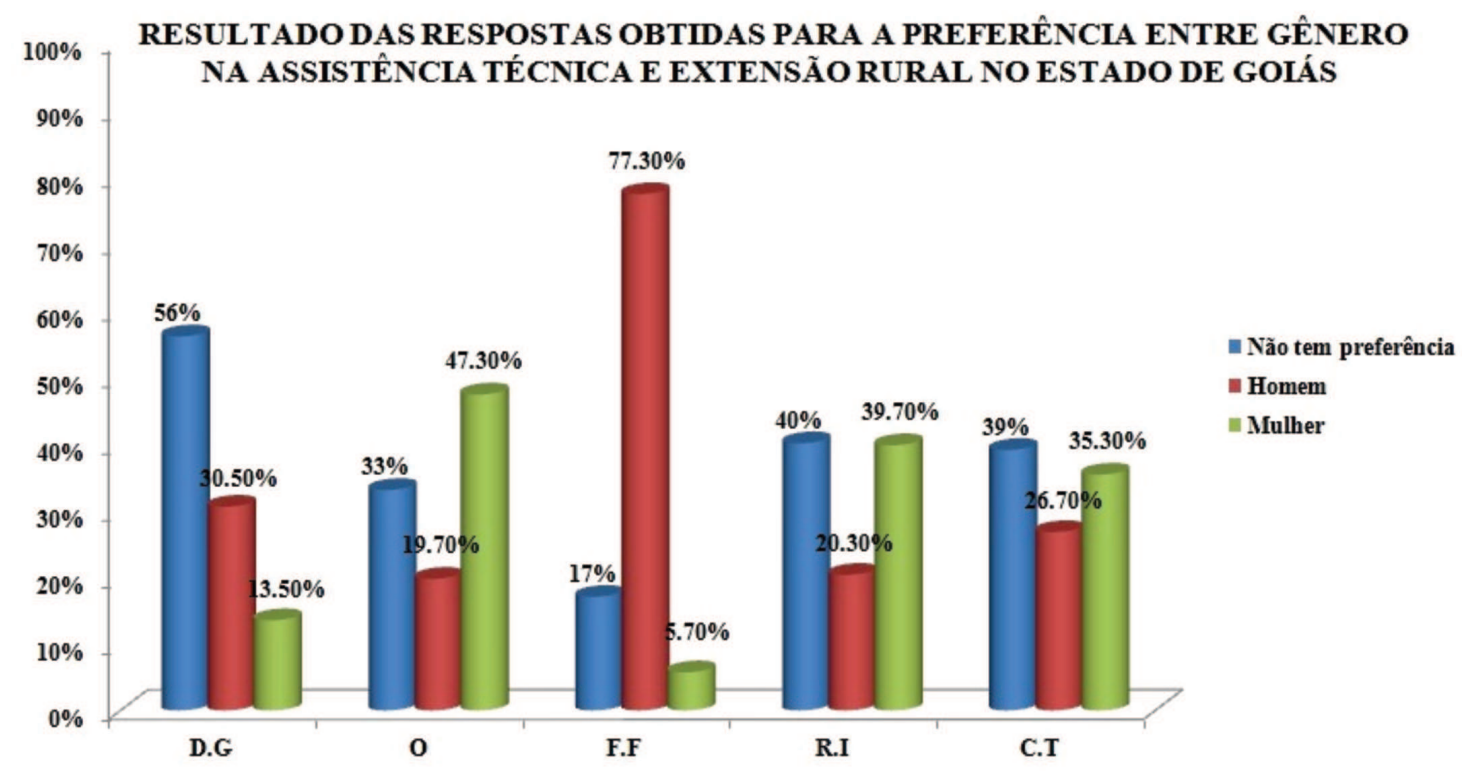

Figura 2. Distribuição das percentagens referentes às alternativas escolhidas pelos proprietários rurais entrevistados, entre os meses de março de 2009 e setembro de 2012, em diferentes Municípios do Estado de Goiás. D.G = Diferença entre gênero; O = Organização; F.F = Força Física; R.I = Relacionamento interpessoal; C.T = Conhecimento teórico. 
inseminação artificial em bovinos no Estado de Goiás, a maior parte dos proprietários tem entre nove e vinte anos de experiência (Gordo, 2011), diferindo dos resultados aqui encontrados, segundo os quais os homens eram, em sua maioria, atuantes na agropecuária por mais de 20 anos.

$\mathrm{O}$ fato de mais de $50 \%$ dos entrevistados considerarem que não existe diferença entre gêneros, quanto à capacidade para atividades de Assistência Técnica e Extensão Rural, reforça a necessidade de analisar essa informação de forma mais criteriosa. Inicialmente, é fato que as mulheres brasileiras têm procurado, cada vez mais, aperfeiçoarem-se ou especializarem-se em determinadas áreas que sustentam o processo produtivo. Um dos reflexos dessa busca é a formação de quantidades expressivas de médicas veterinárias, sugerindo que a maior dedicação aos estudos forma mulheres mais qualificadas e voltadas para o trabalho produtivo, característica, muitas vezes, procurada por produtores rurais (Bruschini \& Puppin, 2004). Outra interpretação que pode justificar a declaração de inexistência de diferença entre gêneros, no quesito capacidade para atividades de Assistência Técnica e Extensão Rural é que, em tempos modernos, é frequente encontrar homens realizando trabalhos domésticos (Ramos, 2009). Logo, confrontando os resultados desta pesquisa com os encontrados na literatura, pressupõe-se que a diferença entre os gêneros é um paradigma, que pode ser conceituado como modelo, padrão ou protótipo (Ferreira, 1971).

Quanto ao tema senso de organização, o maior percentual das respostas indicou que a mulher profissional foi considerada mais organizada no trabalho que o homem, assim como a mulher rural de diversos países e realidades diferentes (Sales, 2007). Segundo o autor, ao mesmo tempo em que as mulheres cuidam da casa, elas também carregam água, cuidam dos pequenos animais, incluindo galinhas, cabras e porcos, além de cuidar das hortas. Alguns apontamentos, porém, sugerem que não é só no meio rural que a mulher tende a ser mais organizada em suas atividades. Por exemplo, juízas do trabalho, que desempenham tripla jornada de trabalho, elevam seu nível de organização, tendo que associar as atividades dentro e fora de casa (Lipp \& Tanganelli, 2002). Todavia, por essa razão, torna-se frequente o aumento dos índices de problemas de saúde da mulher, como o estresse.

Ponderando o tema força física, o fato de as mulheres serem mais afetuosas e frágeis fisiologicamente justifica a escolha dos profissionais do sexo masculino pelos proprietários, quando o trabalho exige maior resistência e performance física. Ainda sobre esse assunto, outra consideração relevante feita pelos entrevistados, e que justifica essa predisposição pela escolha do profissional masculino, fundamenta-se no receio de expor a médica veterinária a situações de risco, que possam gerar danos físi- cos e problemas de saúde a ela. Adicionalmente, sabe-se que os homens possuem maior força muscular que a mulher (Carvalho et al., 1998), além de apresentarem maior afinidade com exercícios físicos rudes (Salles-Costa et al., 2003). Existe uma imagem construída de que as mulheres não realizam trabalhos difíceis e perigosos, por isso, quando a sociedade depara-se com mulheres realizando esse tipo de trabalho, julga não ser o mais apropriado (Messing, 1990). Nessas circunstâncias, deduz-se que as atividades desempenhadas durante Assistência Técnica e Extensão Rural tornam-se inexequíveis, para mulheres.

Outro aspecto importante suscitado nas entrevistas está relacionado com os valores, os quais são, em parte, razões da diferença fundamental entre os gêneros (Oliveira, 1993). Segundo o autor, as mulheres possuem, no centro de sua existência, valores diferentes dos eleitos pelos homens, como ênfase no relacionamento interpessoal, na atenção e no cuidado com o outro, na proteção da vida, na valorização da intimidade e do afetivo e na gratuidade das relações. Nota-se, assim, que a identidade feminina provém da interação com os outros. Daí, serem as mulheres mais intuitivas, sensíveis e empáticas. Na pesquisa, quando a opção por um homem ou por uma mulher deveria ser feita com base em relacionamento interpessoal, as mulheres foram as mais solicitadas.

Por último, analisando-se os resultados obtidos na pesquisa, é notória a conquista de posições, pelas mulheres e, também, pelas Médicas Veterinárias, no ambiente de trabalho rural. Essa conclusão é fruto de uma análise mais criteriosa de todas as respostas aos questionários aplicados, as quais indicaram que a diferença entre gêneros em algumas situações no exercício da Assistência Técnica, não é vista como atitude preconceituosa. Assim, essa situação pode ser interpretada mais como um paradigma do que como um preconceito, pois essa forma de enxergar o trabalho feminino tem sido banida no trabalho realizado por médicos veterinários em campo. Mesmo tendo adentrado recentemente no mundo do trabalho, muitas mulheres já trazem contribuições significativas para o novo paradigma das organizações, que valoriza características como flexibilidade, sensibilidade, intuição, capacidade para trabalhar em equipe e administrar a diversidade (Machado, 2007; Carreira et al., 2001; Gomes, 2005). Estes atributos estão em crescimento constante, assinalando um emergente estilo feminino de liderança.

Assim sendo, é possível inferir que o século XXI estáse iniciando com um perfil de mulher diferente daquele dos séculos anteriores. Talvez, por esse motivo, seja um grande desafio por parte da sociedade preconceituosa e conservadora lidar com a diversidade em um contexto de grandes transformações. Nesse caso, ficou evidente que já existe uma equiparação entre os gêneros, no exercício da Medicina Veterinária, o que, futuramente, pode abrir 
mais amplamente para as mulheres as atividades de extensionistas e assistentes rurais. Considerando-se esse panorama, fica evidente que profissionais médicos veterinários de ambos os sexos podem exercer, com eficiência, atividades como criação de gado de aptidão leiteira, exploração de bovinos de alto mérito genético, produção de pequenos e médios animais e mais uma gama de atribuições relacionadas com o trabalho de campo. Entretanto, na assistência a grandes propriedades, que exploram extensivamente bovinos de aptidão para corte ou situações em que a atividade coloque em risco a integridade física da mulher, o profissional do sexo masculino parece se enquadrar melhor.

\section{CONCLUSÃO}

Existe a percepção de diferenças entre os gêneros, nas atividades de Assistência Técnica e Extensão Rural realizadas por médicos veterinários, quando os aspectos analisados são força física e senso de organização. Nos quesitos relacionamento interpessoal e conhecimento técnico, não houve distinção, ou seja, preferência por profissionais homens ou mulheres. Conclui-se, portanto, que, neste caso, trata-se de um paradigma, e não de um preconceito.

\section{REFERÊNCIAS}

Arshad SS, Muhammad MA, Randhawa IA \& Khalid M (2010) Rural women's involvement in decision-making regarding livestock management. Pakistan Journal of Biological Sciences, 42:162-165.

Bernardo EV, Silva LC \& Lima IS (2010) Assistência técnica e extensão rural e as questões de gênero na perspectiva do desenvolvimento sustentável. In: X Jornada de Ensino, Pesquisa e Extensão, Recife. Anais, JEPEX/UFPE. p.1-3.

Bruschini C \& Lombardi MR (2001) Instruídas e trabalhadeiras: trabalho feminino no final do século XX. Cadernos pagu, 17:157-196.

Bruschini C \& Puppin AB (2004) Trabalho de mulheres executivas no Brasil no final do século XX. Cadernos de Pesquisa, 34:105-138.

Carreira D, Ajamil M \& Moreira TA (2001) Liderança Feminina no Século 21. São Paulo, Cortez. 232p.

Carvalho ACG, De Paula KC, Azevezo TMC \& Nóbrega ACL (1998) Relação entre flexibilidade e força muscular em adultos jovens de ambos os sexos. Revista Brasileira de Medicina do Esporte, 4:2-8.

Dalmina SM, Kaspary ES, Pilar MH \& Falcão ADF (2007) Avaliação da participação das mulheres na propriedade e na geração de renda. Revista Brasileira de Agroecologia, 2:1306-1309.

De Grandi AB (2003) Relações de gênero em famílias agricultoras em Santa Catarina - Brasil. In: Paulilo MIS \& Schimdt W (Eds.) Agricultura e espaço rural em Santa Catarina. Florianópolis, UFSC. p.39-70.

FAO (2009b) Organização das Nações Unidas para Agricultura e Alimentação. Brindging the gap- FAO's programme for gender equality in agriculture and rural development. Disponível em: <ftp://ftp.fao.org/docrep/fao/012/i1243e/i1243e00.pdf>. Acessado em: 20 de setembro de 2012.
Ferreira ABH (1971) Pequeno dicionário brasileiro da língua portuguesa. $11^{a}$ ed. São Paulo, Editora Civilização Brasileira. 2272p.

Gomes AF (2005) O outro no trabalho: mulher e gestão. Revista de Gestão USP, 12:1-9.

Gordo JML (2011) Avaliação da situação da biotécnica inseminação artificial bovina no estado de Goiás. Tese de Doutorado. Escola de Medicina Veterinária e Zootecnia, Goiânia. 93p.

Gupta T, Gupta RK \& Raina KK (2009) Women's involvement in farm activities and their participation in decision making in Jammu \& Kashmir, India. Ecology, Environment and Conservation, 15:495-501.

Hatschbach PI (2011) Os 250 anos da Medicina Veterinária Mundial. Revista Brasileira de Medicina Veterinária, 33:6-6.

IBGE (2006) Censo Agropecuário/ Pesquisa Pecuária Municipal Goiás. Disponível em: 〈www.ibge.com.br〉. Acessado em: 28 de setembro de 2012.

Karam KF (2004) A Mulher na agricultura orgânica e em novas ruralidades. Revista Estudos Feministas, 12:303-320.

Lipp MN \& Tanganelli MS (2002) Stress e qualidade de vida em magistrados da justiça do trabalho: diferenças entre homens e mulheres. Psicologia: Reflexão e Crítica, 3:537-548.

Macedo E \& Santos S (2009) Apenas mulheres? Situação das mulheres no mercado de trabalho em quatro países europeus. Ex æquo, 19:129-155.

Machado CP (2007) A designação da palavra preconceito em dicionários atuais. Dissertação de Mestrado. Universidade Estadual de Campinas, Campinas. 215p.

Messing K (1990) Are women "the weaker Sex" or do just have hard job? The need for research on women's occupational helth. Chronic Diseases in Canada, 2:25-27.

Oliveira RD (1993) Elogio da diferença. O feminino emergente. $2^{\mathrm{a}}$ ed. São Paulo, Brasiliense. 150p.

Paulilo MI (2003) Movimento de mulheres agricultoras: terra e matrimônio. In: Paulilo MIS \& Schimdt W (Eds.) Agricultura e espaço rural em Santa Catarina. Florianópolis, UFSC. p.183210

Pinto G (2006) Mulheres no Brasil: esboço analítico de um plano de políticas públicas para mulheres. In: XIV Encontro Nacional de Estudos Populacionais, Caxambu. Anais, ABEP. p.31-32.

Ramos DP (2009) Pesquisas de usos do tempo: um instrumento para aferir as desigualdades de gênero. Revista Estudos Feministas, 3:861-870.

Riethmuller P (2001) O impacto social da produção animal. In: Madalena FE, Matos LL \& Holanda Júnior EV (Eds.) Produção de leite e sociedade: uma análise crítica da cadeia do leite no Brasil. 1 $1^{\mathrm{a}}$ ed. Belo Horizonte, FEPMVZ. p.103-116.

Rodrigo I (1986) Feminização da agricultura. Análise Social, 22:643-652.

Sales CMV (2007) Mulheres rurais: tecendo novas relações e reconhecendo direitos. Revista Estudos Feministas, 15:437-443.

Salles-Costa R, Heilborn ML, Werneck GL, Faerstein E \& Lopes CS (2003) Gênero e prática de atividade física de lazer. Caderno Saúde Pública, 19:325-333.

Sampaio IBM (2010) Estatística aplicada à experimentação animal. $3^{a}$ ed. Belo Horizonte, Fundação de Estudo e Pesquisa em Medicina Veterinária e Zootecnia. 264p.

Scorzafave LG \& Menezes-Filho N (2006) Caracterização da participação feminina no mercado de trabalho: uma análise de decomposição. Economia Aplicada, 10:41-55.

Rev. Ceres, Viçosa, v. 61, n.1, p. 001-008, jan/fev, 2014 